\title{
Questionnaire survey of women aged 56-59 years: Consultations in general practice, use of hormone replacement therapy (HRT) and participation in screening programmes
}

\author{
Clare Seamark, MRCGP, MFF, General Practitioner; Sue Blake, BSc, Research Assistant, The Honiton Group Practice, Honiton, \\ Devon, $U K$
}

Correspondence: Dr Clare Seamark, The Honiton Group Practice, Marlpits Lane, Honiton, Devon EX14 2NY, UK. Email: cjseamark@doctors.org.uk

(Accepted $16^{\text {th }}$ July 2001)

The Journal of Family Planning and Reproductive Health Care 2002: 28(1): 15-17

\begin{abstract}
Objectives. To ascertain attitudes to consultations in general practice and the gender of the doctor. To determine whether women participate in the National Health Service (NHS) screening programmes available to them and their use of hormone replacement therapy (HRT).

Design. Postal questionnaire survey to women aged 56-59 years.

Setting. The Honiton Group Practice, East Devon, UK. Participants. Two hundred and ninety-four of the 334 eligible women returned the questionnaire (response rate $88 \%$ ).

Main outcome measures. Women's embarrassment on consulting general practitioners $(G P s)$ and preference for a female doctor. Up-to-date cervical smears and mammography screening in eligible women and use of HRT.

Results. A large majority of women $(248 / 294 ; 84.4 \%)$ were not embarrassed when consulting a GP and did not express a preference to see a woman GP for any problem (240/294; $81.6 \%)$. However 123/294 (41.8\%) did express a preference to see a woman doctor for 'women's problems'. Sixty-five women had had a hysterectomy, and 218 of the remaining $229(95.2 \%)$ had had a smear in the past 5 years. For breast screening, 267/294 (90.8\%) had undergone mammography in the previous 3 years. Ninety-three women (32\%) were currently on HRT, and on record searching a total of 146 (49.7\%) had at some time been HRT users.

Conclusions. Embarrassment does not appear to be a major problem for consultations related to female health. A wellorganised general practice with motivated patients can achieve very high uptakes of both cervical and breast screening programmes. Interest in HRT has also risen, with half the women aged 56-59 years having used systemic $H R T$.
\end{abstract}

\section{Key message points}

- Most women in their late fifties are not embarrassed when consulting their GP.

- Most women in their late fifties do not express a preference for a woman doctor for general consultations. However $41.8 \%$ did express a preference for a woman doctor for 'women's problems' and for these women the choice should be available.

- High rates of cervical and breast screening can be achieved in general practice.

- Women in the age group 56-59 years are very interested in HRT, with about half having used systemic HRT.

\section{Introduction}

There have been many changes and advances in screening programmes for women and in the understanding and availability of hormone replacement therapy (HRT) over the last 20 years. It is important to be aware that both the cervical and breast screening programmes are not perfect and they may have adverse effects on the women taking part. 1,2 However, if these screening programmes are to make any impact on mortality from breast and cervical cancer as it seems possible they may be beginning to do, ${ }^{3-6}$ it is important to achieve high uptake amongst eligible women. ${ }^{4,6,7}$ The breast screening programme aims for an uptake of $70 \%$. The higher target for general practitioners (GPs) to attain for cervical screening is an $80 \%$ uptake in their practice. In the Honiton Group Practice there has been a consistently high uptake of screening with over $90 \%$ of eligible women (20-65 years) having regular smear tests and over $80 \%$ (50-65 years) undergoing mammography. A previous study in the practice had also examined some of the reasons why women do not have cervical smears. ${ }^{8}$

The use of HRT by postmenopausal women is also of great interest. Earlier studies have suggested that under $10 \%$ of women aged $40-69$ years in the UK will be current users of HRT, ${ }^{9}$ although there has been a rise in the last few years with $20 \%$ of women aged 45-65 years reporting HRT use in the mid-1990s. ${ }^{10}$ Use rises dramatically amongst postmenopausal women doctors, with $41 \%$ being current users and $47 \%$ having at some time been a user. ${ }^{11}$

The present study sought to discover the level of embarrassment in consulting a GP and whether women prefer a male or female doctor. It also asked about uptake of the NHS screening programmes, and women's use of and views on HRT.

\section{Methods}

The study was set in a semi-rural market town serving a population of 15000 . There are six full-time male partners and five part-time partners of whom four are female. The practice has been a research practice since 1995. The practice records are extensively computerised using the Exeter System. Women aged 56-59 years on 1 December 1999 were identified as the study group. This study was part of a larger study on women's health. The study received approval from the local Medical Research Ethics Committee.

This age group was chosen since most of the participants would be postmenopausal (average age in the UK of 51 years). They would be in the middle of the breast screening 
range and would all have been offered at least one screening appointment. They would also still be part of the cervical screening group.

Postal questionnaires were sent to all 334 women in the selected age range in December 1999, together with a replypaid envelope for the return of the questionnaire. (NB. A copy of the questionnaire is available from the authors on request.) Non-responders were sent a second questionnaire in February 2000.

The questionnaire asked about recent attendance at the practice, about embarrassment when consulting for certain conditions and whether a female doctor was preferred. Further questions were asked about past and current use of HRT, and attendance for cervical and breast screening. The returned questionnaires were then analysed. The practice records were used to complement the questionnaire results.

\section{Results}

Questionnaires were returned by 294/334 women, giving a response rate of $88 \%$. Of these women, $173(58.8 \%)$ reported having seen their GP in the last 3 months. Of the 258 who answered the question on how many times they had seen a GP in the last year the range was 0-12 visits, with a mean of three and median of two visits. Most women were not embarrassed when going to their GP, with only 46 $(16 \%)$ reporting general embarrassment. When asked about specific conditions that might cause embarrassment, vaginal discharge was thought to be most embarrassing with over one-quarter of respondents reporting embarrassment, and attendance for HRT least embarrassing with only six women (2\%) feeling embarrassed. The full results are presented in the Table 1 .

Table 1 The conditions that are most embarrassing when seeing a GP

\begin{tabular}{lll}
\hline Condition & $\begin{array}{l}\text { Women } \\
\text { embarrassed (n) }\end{array}$ & $\begin{array}{l}\text { Women } \\
\text { embarrassed (\%) }\end{array}$ \\
\hline Vaginal discharge & 78 & 26.5 \\
Relationship difficulties & 66 & 22.5 \\
Cervical smear & 53 & 18 \\
Breast lump & 28 & 9.5 \\
Sore throat & 10 & 3.4 \\
Travel advice & 10 & 3.4 \\
HRT & 6 & 2 \\
\hline
\end{tabular}

When asked about the gender of the doctor they were consulting, 54/294 (18.4\%) women preferred to see a woman doctor for any problem and this rose to $123 / 294$ $(41.8 \%)$ if the consultation was for a 'woman's problem'.

Of the 294 women, $65(22 \%)$ had had a hysterectomy and so were not eligible for the cervical screening programme. Of the 229 eligible women, $203(88.6 \%)$ thought they had had a cervical smear in the preceding 5 years, whereas when the records were searched $218(95.2 \%)$ had actually had a smear during that time.

When asked about breast screening, 267 (90.8\%) women said they had been screened in the last 3 years. Ten women in the group were known to have breast cancer with two of the cancers having been detected by screening. Very few women reported any problems with either screening programme.

HRT was currently being used by 93 women (32\%), with $91(98 \%)$ being happy with it. Over three-quarters $(68 / 89$; $76 \%$ ) were using tablets and $21 / 89(24 \%)$ patches. From the records a further 55 women had been prescribed systemic HRT at some stage, bringing the total number women who had ever used HRT to $146(49.7 \%)$. A further 11 women had used topical preparations. Of the 201 women not currently on HRT, who answered the question about why they were not using it, 12 thought they had not reached the menopause, 101 women thought it was not for them at that stage and 22 wanted to know more about it.

\section{Discussion}

One of the strengths of the present study is the extremely high response rate of $88 \%$ obtained from a postal questionnaire. Other studies of women in this age group have had response rates of $74 \%{ }^{10}$ and $80 \%,{ }^{11}$ respectively. The present study is complemented by comprehensive computer records. Obviously those women who answered the questionnaire may be those who are more likely to be interested in their health and partake in screening programmes and explore the possibilities of HRT, though with such a high response rate the possible introduction of bias is less important. It could also be argued that this is a study from just one general practice and may not be representative. However, the practice is large and serves a complete population. The Townsend scores for the town vary from -1 to 1 . There are few women from ethnic minorities.

It is encouraging to see that less than one-sixth of women find a visit to their GP embarrassing. As might be expected, the most embarrassing conditions to go to the doctor with are vaginal discharge and relationship difficulties. Although $18 \%$ of women feel embarrassed when having a cervical smear, the vast majority of these overcame this and only three women in this group had not had a smear in the past 5 years. Reassuringly, fewer women were embarrassed about going with a breast lump, so hopefully they would present early if this occurred. The least embarrassing reason was for HRT, and this may indicate that there is much more openness and awareness of menopausal problems among women and doctors. Ten women indicated that attending with a sore throat or for travel advice was embarrassing. One woman explained this was because she knew she was not supposed to go to the doctor with a sore throat.

Fewer than one in five women prefer to see a female doctor all the time, though this figure more than doubles when they are going about a 'woman's problem'. Other studies have also shown that women were more likely to consult a female rather than a male doctor for problems such as cervical smears, vaginal discharge, breast examination, contraception, and menstrual and menopausal problems. ${ }^{12,13}$ National statistics show that there has been a substantial growth in the number of female GPs from 1988 to 1998 and the number of male GPs has actually decreased. The overall percentage of female GPs in England increased from $24 \%$ in 1988 to $33 \%$ in $1998 .^{14}$ This would suggest that women have more opportunity of seeing a female GP than was previously the case, although over $40 \%$ of practices still do not have a female partner. ${ }^{15}$ Within the Honiton practice over a quarter of appointments are offered by female doctors. Although the practice operates a personal list system, women are encouraged to attend a female partner when they would feel more comfortable and over $80 \%$ of cervical smears are undertaken by the female practice nurses.

The practice continues to have a very high uptake of screening. Just over one in five women in the study had had a hysterectomy, this figure being similar to the national rate. ${ }^{16}$ Of the remaining women in the study eligible for cervical screening, $95.2 \%$ had had a smear in the preceding 5 years. This compares with the national figure for women aged 55-59 years of $82.4 \% .{ }^{17}$ This was actually higher than 
the women remembered, with 15 women believing they had not been screened in the previous 5 years. Breast screening was undertaken in the Honiton area in 1999 just prior to the questionnaire study. In total for the practice, 987/1189 $(83 \%)$ women in the target group attended the NHS breast screening. The overall acceptance of breast screening invitation in England and Wales is currently $76 \%$ of women. ${ }^{5}$ Over $90 \%$ of women who answered the questionnaire had had a mammogram done in the previous 3 years. Most of these women had attended the NHS screening programme, with a few being followed up for previous breast cancer and some having had investigations of breast problems. If these investigations were only shortly prior to the breast screening programme then further mammography was not deemed appropriate. There were only seven women who had had neither breast nor cervical screening.

The current use of HRT at $32 \%$ is much higher than most other studies from general practice, as is the fact that nearly half of the group had used systemic HRT at some stage. ${ }^{9-11}$ This may well reflect the input of the female partners and the ethos of the practice as a whole. There may also be more general changes as understanding and acceptance of HRT increases among women.

Screening programmes have always been seen as a priority by the Honiton practice and the cervical screening programme is co-ordinated by a dedicated practice nurse. Prior to the introduction of breast screening, open evenings with presentations were held in the surgery. Other studies have found that an accurate database is essential and that the attitude of the practice to screening, the beliefs of the individual GPs and their enthusiasm can improve the uptake of breast screening. ${ }^{18,19}$

\section{Conclusions}

The majority of women in the present study did not feel embarrassed when visiting their GP even for what might be considered more intimate problems. Most women did not express a preference to see a female doctor even for 'women's problems', although over $40 \%$ did and their needs should be considered. In a practice with a co- ordinated screening programme and motivated patients, very high rates of uptake of both cervical and breast screening can be obtained. Many women are interested in HRT and the rates of current and past use in the group are much higher than those previously reported.

\section{Acknowledgements}

The authors wish to thank the partners and staff of the Honiton Group Practice and all the women who answered the questionnaire.

\section{Statements on funding and competing interests}

Funding. The Honiton Group Practice is an NHS-funded research practice. Dr Clare Seamark held a RCGP/BUPA Research Fellowship from 1998 to 2000. Both Schering Health Care and Wyeth Laboratories gave grants to support this project.

Competing interests. None declared.

References

Lidbrink E, Elfving J, Frisell J, Jonsson E. Neglected aspects of false positive findings of mammography in breast cancer screening: analysis of false positive cases from the Stockholm trial. BMJ 1996; 312: 273-276.

2 Mittra I, Baum M, Thornton H, Houghton J. Is clinical breast examination an acceptable alternative to mammographic screening? BMJ 2000; 321: 1071-1073.

3 Quinn M, Babb P, Jones J, Allen E, on behalf of the United Kingdom Association of Cance Registries. Effect of screening on incidence of and mortality from cancer of the cervix in England: evaluation based on routinely collected statistics. BMJ 1999; 318: 904-908.

4 Sasieni P, Adams J. Effect of screening on cervical cancer mortality in England and Wales: analysis of trends with an age period cohort model. BMJ 1999; 318: 1244-1245.

5 Reducing the risk. Report of the Breast Screening Programme 2000. NHS. Blonw

prest screenin programme on mortality from breast cancer in England and Wales, 1990-8: comparison BMJ 2000; 321: 665-669.

7 Austoker J Cancer prevention in primary care. London: BMJ Publishing Group, 1995. Seamark CJ. Why women do not present for cervical smears - observations from gener practice. Br J Fam Plann 1996; 22: 50-52.

Wilkes HC, Meades TW. Hormone replacement therapy in general practice: a survey of doctors in the MRC's general practice framework. BMJ 1991; 302: 1317-1320.

herapy: results of a community survey. $F a$

11 Pract 1995; 12: 163-165.

act

Brink-M

-Muinen AVD, Bakker DHD, Bensing JM. Consultations for women's health problems: factors influencing women's choice of sex of general practitioner. Br J Gen Pract 1994; 44 : $205-210$

14 Office for National Statistics (ONS). Statistics for general medical practitioners in England: 1988-1998. Bulletin 1999/13.

15 Hippisley-Cox J, Allen J, Pringle M, et al. Association between teenage pregnancy rates an the age and sex of general practitioners: cross sectional survey in Trent 1994-7. BMJ 2000; 320: $842-845$.

16 Vessey MP, Villard-Mackintosh L, McPherson K, Coulter A, Yeates D. The epidemiology of hysterectomy: findings from a large cohort study, Br J Obstet Gynaecol 1992: 99: 402-407.

Cervical Screening Programme, England: 1998-99. Bulletin 1999/32. NHS, 1999.

Bekker H, Morrison L, Marteau TM. Breast screening: GPs' beliefs, attitudes and practices. Fam Pract 1998; 16: 60-65.

Cook DG, Given-Wilson R, Vecchi P, Poloniecki I. Do general practitioner influence the uptake of breast cancer screening? J Med Screen 1995; 2: 119-124. 